\section{QUEM TEM MEDO DO LIBERALISMO?}

\section{WHO IS AFRAID OF LIBERALISM?}

GATTA, G. Rethinking liberalism for the 21st Century: the skeptical radicalism of Judith Shklar. Routledge: New York, 2018a.

\section{Bruno Camilloto (1) \\ E-mail: brunocamilloto@ufop.edu.br}

(1) Universidade Federal de Ouro Preto; Professor do curso de Direito na graduação e no mestrado 'Novos Direitos, Novos Sujeitos'.

DOI: $10.1590 / 3610714 / 202$

Freedom is no fear, disse Nina Simone. Mas qual o papel do medo na contemporaneidade? Diante da tarefa de pensar sobre o tema, a professora italiana Giunia Gatta ${ }^{1}$ publicou Repensando o liberalismo para o século 21: $\mathrm{O}$ ceticismo radical de Judith Shklar.

A partir da foto de Omran Daqneesh, Gatta convida o leitor a refletir sobre o medo. Omran era uma criança de cinco anos de idade quando o edifício em que estava foi atingido por um ataque aéreo na cidade de Aleppo, na Síria, no dia 17 de agosto de 2016. A foto que circulou nos meios de comunicação revela o menino no banco de uma ambulância, atônito, coberto pela poeira dos escombros e em estado de choque. Provocativamente, Gatta (2018a, p. 06) pergunta: "[...] deve o liberalismo ficar silente diante daquelas circunstâncias trágicas?”. Para a autora, a obra da filósofa Judith Shklar responde negativamente à questão. ${ }^{2}$

O conceito de crueldade é o centro do pensamento de Shklar. Está fundado no sofrimento dos indivíduos e nas suas vozes. Gatta (2018a, p. 02) defende que Putting cruelty first ${ }^{3}$ é algo que deve ser levado a sério pelo pensamento liberal contemporâneo. É a crueldade que permite a articulação entre o ceticismo e o comprometimento político, assumindo a centralidade na vida dos indivíduos, especialmente daqueles marginalizados.
Nascida numa família judia de cultura alemã, em Riga, capital da Letônia, Shklar foi profundamente afetada pela Segunda Guerra mundial, especialmente por ter tido de migrar para Suécia, Japão e Canadá em sua adolescência. Antes de chegar ao Canadá, Shklar passou por um centro de detenção para imigrantes ilegais em Seattle. Seu pensamento político é atravessado pela condição de refugiada, marca de sua compreensão sobre a liberdade. Vida e obra de Shklar são articuladas por Gatta na defesa do argumento mais poderoso do liberalismo do medo: como maior mal e vício supremo na política, a crueldade deve ser reconhecida como o fundamento do medo que justifica o pensamento liberal enquanto forma de proteção dos indivíduos, especialmente em relação àqueles vulneráveis e marginalizados. ${ }^{4}$ Crueldade é "a inflição deliberada de dor física a um ser mais fraco para causar angústia e medo” (Shklar, 1984, p. 08). Mesmo que o comprometimento contra a crueldade seja insuficiente para ofertar soluçóes específicas aos problemas da vida política, ele é um dever do pensamento liberal. A "crueldade é sempre absolutamente intolerável para os liberais, porque o medo destrói a liberdade." (Shklar, 1984, p. 02).

Diante da retomada de perspectivas liberais, bem como do ressurgimento de movimentos ultranacionalistas, xenófobos e conservadores nas esferas públicas nacionais e internacionais, o que o liberalismo deve dizer sobre as injustiças sociais, especialmente sobre as que vitimam e violam o indivíduo? Esta é a colaboração de Repensando o Liberalismo para o Século 21 ao atual debate público. Gatta mobiliza os conceitos de ceticismo e comprometimento como alicerces do liberalismo do medo e defende que a obra de Shklar é progressista, transitando entre um pessimismo incorrigível e um otimismo ingênuo. $\mathrm{O}$ ceticismo se relaciona com a descrença de Shklar em relação ao projeto iluminista. O comprometimento é seu endosso a um projeto teórico e prático de proteção aos indivíduos frente às opressóes que configuram injustiças. É pela radicalização do ceticismo que a relação entre Política e Direito pode se apresentar comprometida com uma proposta liberal protetiva às minorias contra a crueldade e o medo. 
No capítulo 01, Gatta apresenta os eventos biográficos que marcaram o pensamento da filósofa, com destaque para a experiência da Segunda Guerra mundial e as aproximaçóes com outros autores que também viveram os horrores do holocausto. ${ }^{5}$ Com diálogos e debates com professores e filósofos, Shklar teve uma carreira exitosa. ${ }^{6}$ Apesar de seu talento, somente em 1970 se tornou professora em Harvard. Sua produçâo intelectual, sempre ocupada com as barbáries do nazifascismo, é uma ode contra o totalitarismo.

O ceticismo de Shklar é verificado em atitudes práticas, ${ }^{7}$ como em 1982, quando vários professores foram convidados a apoiar uma manifestação contrária à associação de mulheres pró-vida ${ }^{8}$ ao Princeton Women's Center. Em resposta ao convite, Shklar foi assertiva: "Eu devo dizer que apoio fortemente os direitos das mulheres ao aborto, e de fato os direitos dos cidadáos de terem serviços médicos decentes." (Shklar, apud Gatta, 2018a, p. 29). Em seguida, Shklar exercitou seu ceticismo:

No entanto, me parece que essas questôes são problemas altamente controversos, e as mulheres que não compartilham minhas convicçóes religiosas e políticas têm sempre o direito de falar, e falar como mulheres, em suporte à grande parte substancial da população gestante. (Shklar, apud Gatta, 2018a, p 29-30)

A manifestação de Shklar ilustra seu ceticismo como fundamento do liberalismo. Sua carta explicita a impossibilidade de dar apoio por compreender que deve haver diversidade nas manifestaçōes e que é impossível excluir alguém do Princeton Women's Center somente pela posição moral pró-vida. O comprometimento de Shklar com sua proposta teórica produz uma resposta dura: "Eu penso que práticas de exclusão são insensatas bem como repressivas, e eu não posso apoiar você, apesar de eu concordar profundamente com você na questão de mérito." (Shklar, apud Gatta, 2018a, p. 30).

Após a introdução e o capítulo 1, Gatta divide sua obra em duas partes, sendo a primeira composta pelos capítulos 2 e 3 e a segunda composta pelos capítulos 4, 5 e 6 . A parte I é dedicada à reconstruçáo do pensamento de Shklar sobre a Modernidade e propóe uma leitura entremeada pelos conceitos de ceticismo, iluminismo e modernidade propriamente dita. A parte II apresenta o argumento central de Gatta: a defesa do liberalismo do medo no século XXI a partir da relação entre ceticismo e comprometimento.

"No começo, era o Iluminismo" é a frase de Shklar, 2015, p. 03, que inaugura o capítulo 2. Para Gatta, Shklar propóe uma compreensão do Iluminismo para além da ideia da Idade da Razão. After Utopia discute o totalitarismo a partir de uma revisão cética dos valores do Iluminismo. Essa releitura reafirma a autonomia e a dignidade das políticas de resistência contra as forças da fé e da futilidade (Gatta, 2018a, p. 48). O 'indivíduo ordinário' é um dos conceitos centrais, sendo mobilizado contra o conceito de massa. Shklar refuta a individualidade como uma abstração, colocando-a como uma concretização das reivindicaçóes individuais por igualdade.

O capítulo 03 trata do conceito de everyman como resistência às políticas de abstração, ou seja, seu pensamento liberal é voltado para o indivíduo como ser concreto. Audaciosamente, Gatta (2018a, p. 65) diz que After Utopia traz uma argumentação antimoderna que se refletirá nos trabalhos posteriores de Shklar relacionados à resistência contra a ideia do individualismo como abstração.

Sobre Rousseau e Hegel, Gatta destaca a proposta da utopia como um instrumento de crítica de um determinado tempo/lugar. Afasta-se, assim, da ideia de utopia como um esforço deliberado para transformar a história. Gatta sublinha que os escritos de Shklar sobre Hegel são anteriores ao contemporâneo debate entre liberais e comunitários que marca as décadas de 70 e 80 na teoria política. ${ }^{9}$

Se After Utopia inaugurou a tensão entre esperança e desespero, Legalism ${ }^{10}$ é uma defesa do pluralismo, da tolerância e da legalidade ${ }^{11}$ tratados no capítulo 04 do livro. Em Legalism, há um destaque para a relação entre a Política e o Direito a partir do contraste entre a dura realidade contemporânea e alguma forma de nostalgia de lugares e tempos diferentes. O ceticismo de Shklar é definido por Gatta (2018a, p. 92) como a possibilidade de manutenção da tensão entre desespero, a partir de uma leitura antimoderna do Iluminismo, e esperança, sem as ilusóes da modernidade. Shklar 
não se rende às críticas lançadas às principais ideias do Iluminismo, a ponto de cair num niilismo, nem propóe uma perspectiva ingenuamente otimista fincada na fé da razão. Fazendo uma crítica ao liberalismo conservador, ${ }^{12}$ como uma perspectiva que se mantém inerte a respeito do curso dos eventos e das crenças determinadas por forças fora do controle humano, Shklar aposta que o indivíduo deve ser capaz de realizar a ação política a partir de suas próprias experiências.

Sendo a crueldade "a imposição de dor física sobre um ser frágil como forma de causar angústia e medo" (Gatta, 2018a, p. 95), Shklar a coloca como pilar do liberalismo do medo. Em Ordinary Vices, Shklar trabalha os vícios humanos e a condição de vítima ou de ser frágil. Ser frágil é assumir a condição de caminhante que anda pelo campo minado e que em algum momento se tornará vítima diante da inevitável explosão. E quem anda pelo campo minado? $\mathrm{Ou}$, mais literalmente, quem são as vítimas das opressões das diversas formas de poder - públicas e privadas? A incerteza sobre quem são os seres frágeis passíveis de serem considerados vítimas leva Shklar à seguinte resposta: a condiçẫo de vítima é um atributo de toda humanidade, ou seja, todo ser humano possui a capacidade de indignação diante de um ato de crueldade, porque nós somos capazes de perceber que esse ato pode estar potencialmente direcionado a nós. Disso, segue que as vítimas da crueldade são indivíduos ordinários, comuns (Gatta, 2018a, p. 96).

A tensão entre a inevitabilidade dos vícios humanos e a impossibilidade de consentir com eles sobressai como uma tarefa permanente de todo indivíduo, especialmente quando o vício é perpetrado pelos fortes ou poderosos contra os fracos ou vulneráveis. Olhando para o catálogo de vícios humanos, Shklar reivindica Putting cruelty first como exercício fenomenológico direcionado a desestabilizar categorias políticas ossificadas na ideologia, buscando construir um conceito capaz de mobilizar os elementos centrais de seu liberalismo na proteção do indivíduo ordinário (Gatta, 2018a, 98-99).

Shklar faz uma dura crítica ao liberalismo, destacando que ele possui um grande débito com a misantropia. O corolário liberal do governo das leis nasce da observação de que seres humanos, em geral, não são criaturas virtuosas. Relembrando
Maquiavel, Shklar considera a misantropia como um vício político tão pernicioso quanto a crueldade, vez que ela não se importa com os danos causados aos indivíduos, que, aliás, não são nada além de miseráveis espectadores de sua própria glória ou ruína. Daí a necessidade de um comprometimento com alguma perspectiva progressista e legalista que náo tolere a crueldade e que não se acomode diante das situaçóes de injustiça. Aliado ao ceticismo, esse compromisso desafia a inércia conservadora da crença de que os eventos estão determinados por forças alheias ao controle humano. Desafiadoramente, Gatta (2018a, p. 104) propóe:

Minha sugestão provocativa é: Shklar realmente nunca viu seu ceticismo em contraste com seus comprometimentos progressistas para abandonar a crueldade e o medo. E isto é uma importante contribuição para a reconceituação do liberalismo para nossos dias.

O capítulo 5 trata de uma perspectiva agonística para o uso das categorias medo e crueldade. Cotejando Ordinary Vices e Legalism, Gatta (2018a, p. 110) sugere que a instância agonística da política de Shklar é resultado da articulação entre comprometimento e ceticismo. Essa tensão coloca ao indivíduo o desafio prático de mobilizar suas convicçóes no campo político, tornando-se um ser capaz de produzir intervençóes, sem, contudo, a pretensão de que suas convicções sejam tomadas como verdade ou como uma espécie de ordem natural das coisas ou da história.

$\mathrm{Na}$ tentativa de pensar sobre as conexóes entre a moralidade, a Política e o Direito no campo do liberalismo, o ceticismo de Shklar coloca a ética, enquanto espaço não-neutro em relação à compreensão das situaçóes de injustiça, em perspectiva política. Esse movimento intelectual também é fundamental para compreensáo do Direito como um espaço que não pode ser caracterizado pela neutralidade em relação à paisagem política que ajuda a construí-lo (Gatta, 2018a, p. 110).

Não existindo por si mesmo, o Direito não é autojustificável. Ele deve sempre ser visto e revisto em conexão com a moralidade e a Política. Legalism é uma crítica (i) ao Direito Natural como ideologia de 
consenso, (ii)à inabilidade do Positivismo Jurídico ${ }^{13}$ de reconhecer sua própria posição como uma forma de ideologia e (iii) à geral exposição da legalidade como ideologia 'por si mesma' nos julgamentos políticos internacionais (Gatta, 2018a, p. 111). Rejeitando a ilusão da neutralidade do Direito, Legalism defende a legalidade como uma posição ideológica dentre outras: a proteção de 'minorias permanentes'. Não estando fundado numa concepção de indivíduo forte, independente e empoderado, a legalidade deve estar voltada à proteção dos sujeitos não-empoderados, abusados e intimidados (Gatta, 2018a, p. 111). Shklar propóe que a legitimidade da legalidade deriva da possibilidade de ela ser instrumento de políticas de tolerância e de pluralismo prioritárias num Estado de Direito.

O capítulo 6 argumenta sobre como uma leitura agonística contribui para dar sentido à centralidade das vozes marginalizadas na perspectiva do liberalismo do medo. São essas vozes que redimensionam os conceitos de justiça e cidadania por meio da ação prática na dimensão política. Retomam-se o indivíduo e o liberalismo como as melhores perspectivas para empoderar e proteger os vulneráveis e excluídos. A luta por proteção jurídica:

[...] nasce num contexto específico, um contexto que é afetado pelas configuraçôes morais e políticas do poder. Que ele [o Direito] seja um instrumento indispensável em uma sociedade liberal não significa que ele não deva ser discutido criticamente. (Gatta, 2018a, p. 127)

A partir do pensamento de Montaigne sobre as guerras religiosas, Shklar faz análise das atrocidades (torturas e massacres) resultantes das duas guerras mundiais. O liberalismo do medo é cético em relação à possibilidade de a realidade ser conformada por uma ordem normativa estável, tal como proposto pelo liberalismo de direitos. Para Gatta (2018a, p. 118), em Shklar as vítimas são capazes de desafiar a gramática e a semântica da realidade que as constituem. As vozes das vítimas são o esforço político que ecoam na esfera pública, denunciando politicamente a crueldade a que estão submetidas. Por isso, o liberalismo do medo não é um liberalismo sem esperança, mas um liberalismo sem ilusôes, no qual os direitos são instrumentos indispensáveis para proteção das vítimas. ${ }^{14}$

Relacionando o radicalismo cético ao conceito de cidadania das obras The Faces of Injustice e American Citizenship, Gatta (2018a, p. 125-126) afirma que, numa sociedade liberal, a cidadania deve significar olhos e ouvidos atentos aos abusos de poder do Estado e das Corporaçóes. Em suas palavras:

Aqui, literal e diretamente, as margens falam, suas vozes reivindicam, e suas reivindicaçóes - de acordo com Shklar - devem ser simples e diretamente ouvidas, seus valores transcendem aquilo que está estabelecido conforme o Direito, fazendo uma rica contestação política. (Gatta, 2018a, p. 127)

Observando a história das injustiças produzidas pela escravidão nos EUA e tendo em conta sua condição de mulher branca, refugiada, esposa, mãe e professora, Shklar mantém os olhos abertos e os ouvidos atentos às injustiças dentro e fora do contexto da sociedade norte-americana. ${ }^{15}$ American Citizenship explicita as contradiçóes da ideia de cidadania a partir dos conceitos de trabalho, status social e classe. Além do exercício das liberdades negativas, a cidadania deve estar comprometida com a ação protagonizada pelos cidadãos, especialmente por aqueles à margem. Essa proposta indica que, além da necessária dimensão formal, os direitos ao trabalho e ao voto devem ser compreendidos como possibilidade teórica e prática de eliminação das situações de crueldade. À dimensão formal alia-se a dimensão econômica da cidadania, vez que "o direito de ganhar sua própria vida, efetivamente aumenta o escopo da cidadania para incluir a independência econômica." (Gatta, 2018a, p. 136). Cidadania é um estado de alerta sobre as avenidas que podem ser abertas pela crueldade, especialmente em relação aos mais vulneráveis. Se, por um lado, instituiçôes como o Direito são cruciais para a defesa dos indivíduos, por outro, elas não são suficientes.

O liberalismo do medo reivindica proteção ao indivíduo por meio de direitos para minorias permanentes e se preocupa com as vozes das vítimas das opressóes (Gatta, 2018a, p. 127). O ceticismo radical é direcionado para a opinião predominante sobre o 
que é justo, o que é possível e o que é inescapável, como forma de abrir espaços de contestação ao status quo. Shklar póe foco no potencial de falibilidade da justiça em vez de buscar a crença no seu triunfo. Os direitos não são apenas fronteiras neutras entre indivíduos iguais, mas, também, instrumentos de defesa dos mais fracos frente aos mais poderosos.

Como elemento agonístico, o sentimento de injustiça pode ser produzido de formas diferentes como, por exemplo, pela fortuna da vida, por um desastre natural ou por condições sociais. Contudo, em todas essas experimentaçôes humanas há uma pergunta fundante e inquietante: o que é um sentimento de injustiça? (Ventura, 2018, p. 80-81). Na mobilização das respostas possíveis à questão da injustiça, Gatta (2018a, p. 123) argumenta que "O liberalismo é justificado por ser o melhor equipamento (instrumento) para empoderar e proteger os vulneráveis e excluídos.". Não por acaso que The Faces of Injustice aponta para tarefa política de transformar em injustiça aquilo que é 'apenas' hostilidade e má sorte. A partir da ênfase na distinção entre injustiça e má sorte, Shklar novamente traz ao centro do liberalismo do medo seu protagonista: a vítima.

O século XXI é inaugurado pelos atentados às torres gêmeas do World Trade Center em 2001, em Nova York, seguido da invasão do Iraque em 2003. Em 2008 a crise financeira do mercado imobiliário norte-americano impactou a economia mundial interferindo na situação social de vários indivíduos ao redor do mundo. As diversas guerras no oriente médio, em especial da Síria e da Líbia em 2011, e os desastres naturais, como o terremoto no Haiti em 2010 e o Tsunami no Japão em 2011, também se destacam como situaçóes sociais que podem ser compreendidas como hostilidade e má-sorte. Em 2015 a crise dos refugiados impactou o mundo, especialmente a Europa, cujo símbolo foi a chocante foto do menino Alan Kurdi, ${ }^{16}$ morto por afogamento numa praia da Turquia. Por fim, ainda sem a pretensão de apresentar um catálogo completo de situaçóes dramáticas experimentadas pela humanidade no século XXI, a pandemia produzida pelo Coronavírus (COVID-19) que matou 654.309 pessoas no mundo. ${ }^{17}$

Se o liberalismo é um conceito em disputa ao longo do tempo, não seria diferente no século XXI (GATTA, 2018b). Pensar e repensar os fundamentos de uma sociedade que possa ser denominada 'liberal' é uma tarefa que se impóe a toda pessoa que se coloque a refletir sobre a legitimidade do uso do poder e da coerção. Shklar cumpriu essa tarefa a partir de sua experiência/pensamento ao longo do século 20. A partir da pergunta "o liberalismo do medo pensado por Shklar tem alguma coisa a dizer sobre a crueldade infligida às pessoas, especialmente às minorias permanentes, na contemporaneidade?" Gatta cumpre aquela tarefa como reflexão prospectiva para o século XXI.

É possível ser cético e comprometido ao mesmo tempo? Com Gatta (2018a), podemos responder afirmativamente à pergunta. Putting cruelty first é apostar num ceticismo radical diante da história dos indivíduos e das sociedades, identificando as vulnerabilidades a que todos os seres humanos comuns estão submetidos. Mas é, também, não se conformar com uma ordem natural das coisas, nem com um determinismo histórico, para reivindicar na esfera pública a eliminação das circunstâncias de opressão impostas às minorias permanentes.

As vozes das minorias devem ser escutadas, viabilizadas e levadas em consideração como forma de revisão política da estrutura jurídica e proteção dos indivíduos comuns ante às opressóes oriundas das estruturas de poder. Sendo o medo um sentimento comum a todos os indivíduos, a crueldade é a raiz conceitual que fundamenta o ceticismo radical apontando para a necessidade de proteçáo do indivíduo.

A foto de Omran simboliza um tema da contemporaneidade: o medo oriundo da crueldade a que a vítima, uma criança, foi exposta. Se a definição Freedom is no fear fizer algum sentido para o leitor, o livro de Giunia Gatta é uma obra indispensável para lançar luzes no debate público sobre o liberalismo no século XXI.

\section{Agradecimentos}

Agradeço à editora Routledge que disponibilizou um exemplar do livro Rethinking Liberalism for the 21st Century. The Skeptical Radicalism of Judith Shklar para elaboração desta resenha. Agradeço também aos diálogos com Elydia Monteiro, Giulle Vieira, Hélio Oliveira Júnior, Lucas Petroni, Ludmilla Camilloto, Marcus Paulo Barbosa, Raíssa Ventura e Sérgio da Mata. 


\section{Notas}

1 Giunia Gatta é professora do Departamento de Análise Política e Gestão Pública da Universidade de Bocconi, Itália.

2 Gatta (2018a) apresenta uma vasta bibliografia sobre Shklar. Para os objetivos desse trabalho, o foco será nas obras: After Utopia: The Decline of Political Faith (Shklar, 2015); Legalism: Law, Morals, and Political Trials (Shklar, 1964), The Liberalism of Fear (Shklar, 1989a), The Faces of Injustice (Shklar, 1990) e American Citizenship (Shklar, 1991). Daqui em diante utilizarei nomenclatura abreviada para duas obras: After Utopia e Legalism.

3 Putting Cruelty First é o título do primeiro capítulo de Ordinary Vices. Inicialmente, fiz a tradução deste título por 'colocando a crueldade em primeiro lugar'. Contudo, ao longo do texto, a traduçáo literal não foi capaz de expressar o sentido do conceito de Shklar, motivo pelo qual preservei o termo no original.

4 Liberalism of permanent minorities.

5 Por exemplo, Primo Levi.

6 Shklar possuía grande habilidade para lecionar aos seus alunos.

7 Nos dizeres de Gatta (2018a, p. 26), a trajetória acadêmica de Shklar é o exercício da "teoria política como vocação.”.

8 Movimento de mulheres contrárias ao aborto.

9 Como estabelecido na literatura da filosofia política, especialmente na teoria política norte-americana, as décadas de 70 e 80 foram marcadas pelo debate entre o liberalismo e o comunitarismo. O primeiro, sob a influência do pensamento de Kant, se sustenta no princípio da autonomia individual sendo caracterizado criticamente pela ideia de 'atomismo'. O segundo, sob a influência do pensamento de Hegel, se sustenta no argumento da organicidade da sociedade sendo caracterizado pela 'totalidade da comunidade'. Gatta alerta que a leitura de Shklar do pensamento de Hegel é um movimento crucial para o estabelecimento de seu argumento no tocante às 'margens do liberalismo', sem, contudo, fazer parte daquele contexto dos debates entre liberais e comunitários.

10 O termo legalism utilizado em minúsculo no texto de Shklar será traduzido aqui por legalidade.

11 Legalism é uma defesa da legalidade como forma de proteção das minorias permanentes contra as opressóes, especialmente aquelas produzidas pelo Estado.

12 Para Shklar (2015) são expoentes do liberalismo conservador Wilhelm Röpke, Friedrich Von Hayek, Bertrand de Jouvenel, Michael Polanyi, Alfred Cobba, e Ludwig von Mises. Para aprofundar no contexto dessa proposta conceitual ver o capítulo VI de After Utopia.

13 Shklar fez um interessante debate com Austin, Kelsen e, especialmente, Hart.

14 Reivindicar que os indivíduos possuem direito de falar só faz sentido se considerarmos que aquelas vozes possuem esperança. Citando Wittgenstein, Ventura (2018, p. 09) sustenta que "Pode falar quem tem esperança, e vice-versa.".

15 Shklar (1989b, 1990) não teorizou nem o racismo nem o feminismo. Esses temas, contudo, não passaram desapercebidos aos seus olhos, especialmente em American Citizenship.

16 Omran e Alan, duas imagens de crianças e um mesmo sentimento: a crueldade.

17 Dado quantitativo de 29 de julho de 2020.

\section{REFERENCLIAS}

GATTA, Giunia. (2018a), Rethinking liberalism for the 21st century. The skeptical radicalism of Judith Shklar. Routledge: New York.

GATTA, Giunia Valeria. (2018b), Shklar made me do it! The liberalism of fear and international intervention. Rivista quadrimestrale" 2/2018, pp. 261-282. Disponível em: <https://www.rivisteweb.it/doi/10.4479/90792>. Acesso em: 05.01.2020.

SHKLAR, Judith N. (2015), After Utopia: The Decline of Politcal Faith. Princeton: Princeton University Press. Disponível em: muse.jhu.edu/book/43403. Acesso em: 05.01.2020.

SHKLAR, Judith N. (1964), Legalism (an essay of Law, Morals and Politics). London: Oxford University Press.

SHKLAR, Judith N. (1984), Ordinary Vices. Massachusetts: Harvard University Press.

SHKLAR, Judith N. (1989a), Liberalism of fear. In: ROSENBLUM, Nancy L. Liberalism and the Moral Life. HARVARD UNIVERSITY PRESS: Cambridge, Massachusetts, 1989, p. 21-38.

SHKLAR, Judith N. (1989b), A life of learning. Charles Homer Kaskins Lecture of 1989. American Council of Learned Societies. Washington, D.C. April 6, 1989 ACLS OCCASIONAL PAPER, No. 9. Disponível em: https://publications.acls.org/OP/Haskins_1989_ JudithNShklar.pdf. Acesso em: 03.01.2020.

SHKLAR, Judith N. (1990), The Faces of Injustice. Yale University Press.

SHKLAR, Judith N. (1991), American Citizenship. The quest for inclusion. Massachusetts: Harvard University Press. 
SHKLAR, Judith N. (2015), After Utopid: The Decline of Political Faith. Princeton: Princeton University Press. Disponível em: muse.jhu.edu/book/43403. Acesso em: 20.01.2020

VENTURA, Raíssa Wihby. (2018), O outro nas fronteiras. Para uma teoria política da migração. Tese (Doutorado em Ciência Política) - Faculdade de Filosofia, Letras e Ciências Humanas, Universidade de São Paulo, São Paulo, 2018. doi:10.11606/T.8.2019.tde-09052019103345. Acesso em: 2020-02-10.

Resenha recebida em: 06/06/2020 Aprovado em: 28/09/2020 